\title{
Active learning in optics and photonics (ALOP): a model for teacher training and professional development
}

Minella Alarcon, Zohra Ben Lakhdar, Ivan Culaba, Souad Lahmar, Vasudevan Lakshminarayanan, et al.

Minella Alarcon, Zohra Ben Lakhdar, Ivan Culaba, Souad Lahmar, Vasudevan Lakshminarayanan, Alexander P. Mazzolini, Joel Maquiling, Joseph Niemela, "Active learning in optics and photonics (ALOP): a model for teacher training and professional development," Proc. SPIE 7783, Optics Education and Outreach, 778303 (20 August 2010); doi: 10.1117/12.860708

SPIE Event: SPIE Optical Engineering + Applications, 2010, San Diego, California, United States 


\title{
Active learning in optics and photonics (ALOP): A model for teacher training and professional development
}

\author{
Minella Alarcon, United Nations Educational, Scientific and Cultural Organization (France); \\ Zohra Ben Lakhdar, Univ. El Manar (Tunisia); Ivan Culaba, Ateneo de Manila Univ. \\ (Philippines); Souad Lahmar, Institut Preparatoire aux Etudes Scientifiques et Techniques \\ (Tunisia); Vasudevan Lakshminarayanan, Univ. of Waterloo (Canada); Alexander P. Mazzolini, \\ Swinburne Univ. of Technology (Australia); Joel Maquiling, Ateneo de Manila Univ. \\ (Philippines); Joseph Niemela, The Abdus Salam International Ctr. for Theoretical Physics (Italy)
}

\begin{abstract}
Based on physics education goals adopted at the 2005 World Conference on Physics and Sustainable Development, the workshop on "Active learning in optics and photonics (ALOP)" has been described as a model for teacher training and professional development. This paper describes the basic philosophy and elements of the workshop and how it has served physics teachers in schools and introductory college/university in the developing world. Its main philosophy of fostering modern hands-on learning techniques-- adapted to local culture, needs and availability of teaching resources-- is elaborated. The workshop provides the participants with a conceptual evaluation instrument, drawn from relevant physics education research, giving teachers an important tool to measure student learning.
\end{abstract}

Keywords: active learning, inquiry-based approach, optics, photonics, assessment, teacher training, in-service training, developing countries, introductory university physics, conceptual learning, Africa

\section{1) A COHERENT MODEL OF "ACTIVE LEARNING IN OPTICS AND PHOTONICS (ALOP)"}

Based on physics education goals adopted at the 2005 World Conference on Physics and Sustainable Development, the workshop on "Active learning in optics and photonics (ALOP)" has been described as a model for teacher training and professional development ${ }^{1}$. In 2003, the ALOP workshop was designed and developed by an international team that shares teaching experiences from different educational environments, cultures and needs. Optics and Photonics is chosen as a coherent and self-contained theme which can be explored in an inherently interesting set of topics that can be taught at almost any time in an introductory physics course. If taught as an introduction to a physics course optics can be used as an inspirational and motivational tool that can help engage students in the rest of the course. The ALOP workshop introduces the active learning pedagogy via six modules that cover basic topics in Geometrical Optics, Lenses and Optics of the Eye, Interference and Diffraction, Atmospheric Optics and Optics in Communication. The topics studied in the five-day ALOP workshop explore many important concepts which build sequentially from basic fundamentals of geometric and wave optics, through to important applications, such as optics of the eye, and atmospheric optics effects, and finally to optical communications, that brings together many of the ideas covered in previous modules and explores a topic of great significance to modern life. Optics has been identified in this project as having the potential for low-cost hands-on learning to introduce and stimulate young people from the developing world into science. The topics are presented in such a way that teachers are provided with tools for motivating student learning and lectures are replaced with sequenced activities based on direct observation of physical phenomena. The active learning pedagogy integrates conceptual questions and handson activities with practical applications that help students understand their everyday world. The active learning model used in the ALOP workshop is one that encourages students to construct their understanding of fundamental concepts via a predict-observe-discuss-synthesize (PODS) learning cycle. Participants in the workshop learn about the active learning pedagogy, as well as physics education research showing the efficacy of active learning, and most importantly undergo first-hand the full "student experience" of active learning classes and the PODS learning cycle. The project has been designed to be practical and affordable. The materials used in the activities are generally simple, inexpensive and available in most countries. Equipment may be locally fabricated. The Light and Optics Conceptual Evaluation (LOCE) is being developed as part of the program to assess the learning gains of the participants. So far,

Optics Education and Outreach, edited by G. Groot Gregory, Proc. of SPIE Vol. 7783

$778303 \cdot$ ? 2010 SPIE · CCC code: 0277-786X/10/\$18 · doi: 10.1117/12.860708 
the results provide an idea of how much the workshop has helped the participants to improve their conceptual understanding of optics. The five-day workshop follows a training manual which provides inquiry materials, teacher guides and apparatus plan that can be translated into local languages and adapted to meet local needs. To date, the training manual has been translated from its original English version into French, Spanish and Arabic.

\section{2) TRAINING TRAINERS AROUND THE WORLD}

Projections by the UNESCO Institute of Statistics (UIS) ${ }^{2}$ indicate that 27 out of 45 countries in sub-Saharan Africa face a critical teacher shortage. According to UIS estimates, 96 out of 195 countries will need at least 1.9 million more teachers in classrooms by 2015 than in 2007. The 2010 Education for All Global Monitoring Report has called for "strengthening of the learning environment by providing highly skilled teachers".

We can only deduce from this information that the particular situation in science education cannot be any better. There is a critical need to train trainers of science and mathematics teachers all over the world.

The ALOP workshop advocates for renewing the way physics is taught and improving conceptual understanding of fundamental optics principles. Since 2004, trainers of physics teachers in introductory university physics and secondary school in developing countries have benefited from thirteen ALOP workshops organized under the supervision of UNESCO. Four of them have been organized in sub-Saharan African countries and three in North Africa. More than 400 physics teachers, including 130 women, from 45 countries (15 in Africa) have participated in these workshops. Indeed, the workshop has been received with enthusiasm in many countries.

In addition to the UNESCO-organized ALOP workshops, ALOP-trained trainers have initiated follow-up workshops locally in Morocco, Tunisia, Argentina and Peru, and have disseminated the active learning pedagogy through optics and photonics. It is in Morocco that the advocacy has been most successful so far. The follow-up training-of-trainers ALOP workshops have attracted about a thousand physics teachers from universities and secondary schools since 2006. This number is expected to increase considerably, as the Moroccan Emergency Programme 2009-2012 for national reform in education is being implemented. There is a proposal to adopt part of the ALOP curriculum for the training of physics teachers in all Moroccan secondary schools.

To measure the learning gains of the participants and have an idea of how successful the ALOP project has been in training trainers, the Light and Optics Conceptual Evaluation (LOCE) has been administered at every workshop. The data obtained from the LOCE results were analyzed statistically, taking particular care that only questions having direct relation to the modules taken up in the ALOP workshops were used in the analysis.

The statistical tests have shown that a significant difference between pre- and post-scores is achieved at each workshop. Taking LOCE results from 11 workshops, Figure 1 compares the total pre-score and the total post-score. 


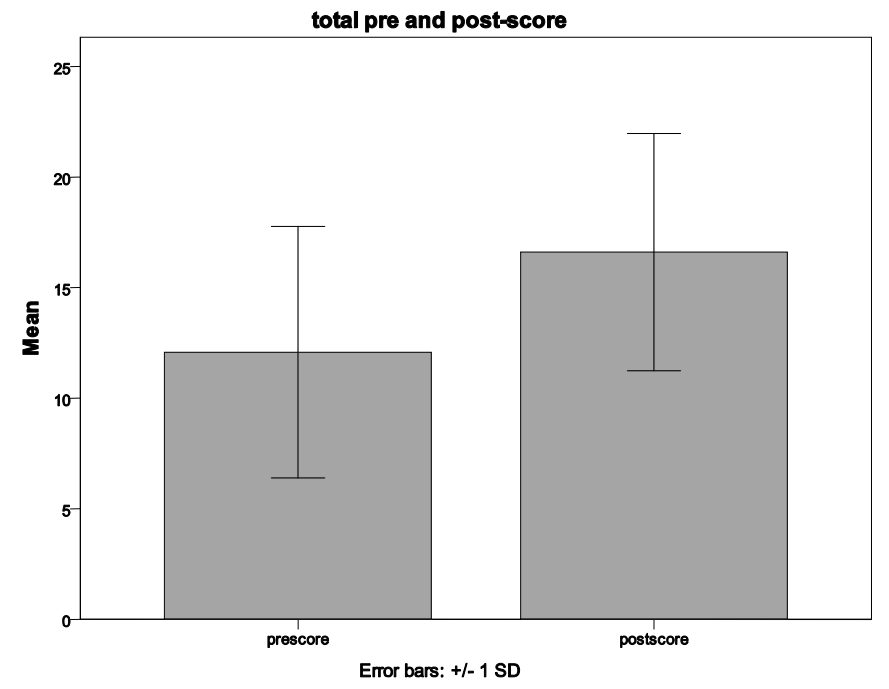

Figure 1. Total pre-score and total post score from LOCE results are compared. Significant difference $(\mathrm{p}=0.000)$ is found between total pre-score and total post score

\section{Statistics}

Pre-score

\begin{tabular}{|ll|r|}
\hline N & \multicolumn{1}{c|}{ Valid } & 280 \\
Mean & Missing & 0 \\
Median & & 12.08 \\
Mode & 11.50 \\
Std. Deviation & 10 \\
Variance & 5.682 \\
Skewness & 32.288 \\
Std. Error of Skewness & .422 \\
Kurtosis & .146 \\
Std. Error of Kurtosis & -.544 \\
Range & & .290 \\
Minimum & & 25 \\
Maximum & & 2 \\
Percentiles $\quad 25$ & 8.00 \\
& 50 & 11.50 \\
& 75 & 16.00 \\
\hline
\end{tabular}

Statistics

\begin{tabular}{|c|c|c|}
\hline \multicolumn{3}{|l|}{ Post-score } \\
\hline $\mathrm{N}$ & Valid & 280 \\
\hline & Missing & 0 \\
\hline \multicolumn{2}{|l|}{ Mean } & 16.60 \\
\hline \multicolumn{2}{|l|}{ Median } & 16.00 \\
\hline \multicolumn{2}{|l|}{ Mode } & 13 \\
\hline \multicolumn{2}{|c|}{ Std. Deviation } & 5.368 \\
\hline \multicolumn{2}{|c|}{ Variance } & 28.814 \\
\hline \multicolumn{2}{|l|}{ Skewness } & .083 \\
\hline \multicolumn{2}{|c|}{ Std. Error of Skewness } & .146 \\
\hline \multicolumn{2}{|c|}{ Kurtosis } & -.304 \\
\hline \multicolumn{2}{|c|}{ Std. Error of Kurtosis } & .290 \\
\hline \multicolumn{2}{|c|}{ Range } & 34 \\
\hline \multicolumn{2}{|l|}{ Minimum } & 2 \\
\hline \multicolumn{2}{|l|}{ Maximum } & 36 \\
\hline \multirow[t]{3}{*}{ Percentiles } & 25 & 13.00 \\
\hline & 50 & 16.00 \\
\hline & 75 & 21.00 \\
\hline
\end{tabular}

Table 1. Descriptive analysis of total pre-score and post-score from 11 workshops corresponding to Figure 1. 
Table 1 provides the details of the statistical treatment of LOCE total pre-score and post-score from 11 workshops. It should be noted that tests administered before November 2008 were all given in English even if this was not the mother tongue of the participants. Therefore, it is possible that the lack of language skills may have influenced the pre and post test results. Nevertheless, the result illustrated by Figure 1 and Table 1 agrees with the participants' evaluation and perception that the workshop improved their own level of understanding of optics and photonics. The improvement is encouraging as most participants in the ALOP workshops are already experienced physics teachers (some with particular expertise in optics). One would expect even more significant improvements in students taught via active learning. LOCE pre- and post-test results have the potential of showing significant improvement in the teaching (and learning) of fundamental competencies in optics \& photonics education of teacher participants across continents, across cultures and across languages (French, Portuguese, Spanish, English, etc).

\section{3) WHAT PARTICIPANTS SAY ABOUT THE ALOP WORKSHOP}

In November 2006, an evaluation questionnaire was designed to record the anonymous comments and suggestions of the participants about the ALOP workshop. Participants respond to the questions on the last day of the workshop. For this paper, we reviewed the responses of 241 participants from the ALOP workshops in New Delhi (India), Dar es Salaam (Tanzania), Sao Paulo (Brazil), Lusaka (Zambia), Douala (Cameroon), Bogota (Colombia), Kathmandu (Nepal), Santiago (Chile) and Constantine (Algeria).

Initially, all participants were asked to define in their own words what is meant by "active learning". The most common answers cited the active participation of each student during the lesson (52 respondents), as well as the central role of experiments and hands-on activities (56 participants). The importance of interaction and discussion with fellow students and with the teacher was mentioned by many participants (32 respondents). It was also pointed out that students are constructing their knowledge by themselves ( 25 respondents). Some participants ( 16 respondents) gave the different steps of the learning method: "prediction, experiment, observation, discussion, conclusion". For 13 respondents, the prediction part seems to be the most important in this teaching method. Participants also commented on the role of teachers and students: the student is at the centre of the learning process ( 10 respondents) and the teacher, as a guide and facilitator, helps the student to construct his knowledge (14 respondents). Furthermore, ten respondents, mostly from Algeria, pointed out that active learning is a simple, efficient and fast method of teaching. Few participants (10 respondents) also answered that it is a minds-on method, where the students are thinking actively.

When asked if "active learning" could improve their students' understanding of physics, most participants responded positively. They pointed out that "active learning" is hands-on and mind probing, so that students can understand more easily and remember better what they are taught. The participants confirmed that it is good for them to be able to observe phenomena, which are applications of the theory. This method of teaching increases students' curiosity, enthusiasm and motivation. In this mode of learning, students discuss with fellow students and teachers in order to make predictions, do experiments, observe, and draw conclusions- this is the way scientists do science. They construct knowledge instead of simply memorizing facts.

In an active learning environment, it is essential for students to participate actively in the discussions and learning activities. Most participants felt that they had the opportunity to actively participate. The average level of participation in most workshops (except those held in Algeria and Cameroon) was higher than 8, on a scale where 10 is the highest level. Some participants were satisfied with their level of active participation. Others gave different reasons for not always actively participating, such as insufficient time to allow all participants to speak, tiredness, low background in the field.

Almost all respondents reported that the workshop improved their own level of understanding of optics and photonics. Only five participants responded that it did not, including three who were more interested in improving their ways of teaching. 
A majority of participants specified the modules that interested them most: optical transmission of data (for 81 participants), followed by wavelength division multiplexing (66), atmospheric optics (57), and interference and diffraction (52). The other modules are on geometrical optics and optics of the eye.

After the workshop, participants are expected to spread the word about the innovative pedagogy of "active learning" and influence their fellow teachers. In the ALOP workshops in Algeria, Cameroon, Chile, Colombia, Nepal, Tanzania, and Zambia, more than $95 \%$ of the respondents thought that their fellow teachers would be influenced if they did these modules in their institutions. In ALOP New Delhi 2006, around 30\% of respondents said that fellow teachers would not be influenced, mostly because of the difficulty to retrain teachers in traditional institutions. In ALOP Sao Paulo 2007, almost $40 \%$ of the respondents answered that they probably could not influence their fellow teachers, essentially because their colleagues already have their own teaching methods, and are not very open to changing them.

Almost all participants reported that they will be able to redo the modules by themselves, and that they can perform these modules for students in class, because they were clearly explained and are very simple to perform. However, two modules are more difficult to redo in their institutions: optical transmission of data (for 83 participants) and wavelength division multiplexing (for 93 participants), mostly because of the unavailability of material.

The aspects about the workshop that the participants liked most were the experimental part and the observations (mentioned by 77 participants). They also liked making predictions (mentioned by 30 participants). They liked the materials used, especially because these were simple and affordable ( 27 participants). They enjoyed the interaction, cooperation, and constructive discussion with fellow participants and with the facilitators ( 25 participants). Two other aspects that were appreciated were the kindness, enthusiasm and charisma of facilitators, which created a great atmosphere (20 participants), as well as the good methodology of teaching and transmitting information (18 participants). Other positive aspects of the workshop included, the active participation of the learners (14 participants), the discussions of the results (13 participants), the good experience of the facilitators (7 participants), the way of explaining concepts using simple experiments (6 participants), the team work (5 participants), magic tricks ( 5 participants), and the overall organisation (4 participants from Colombia).

When participants were asked which aspects of the workshop they liked the least, 56 answered "none". However one aspect that seems to be a particular problem in all workshops is time management (mentioned by 52 participants). More specifically it was pointed out that there were too many topics to be taken up in too short a time, resulting in speeding up for some topics, or not having enough time to discuss and conclude some modules. For the workshops in Chile and Colombia, which were done in English and Spanish, 11 people indicated that some participants had difficulties with English, and that time was lost in translation. Several participants (10) reported poor class management and/or non-constructive discussions. A number (6) did not like the predictions part. Some specific problems were also cited: not enough breaks (4 participants of workshops in Cameroon and Brazil), too many participants in a group (4 participants of workshops in India and Colombia), too few sets of equipment (5 participants of workshops in Tanzania and Nepal), and uncomfortable classroom conditions (6 participants of workshops in Zambia, Brazil, and Chile).

Participants were also asked how the workshop could be improved. Time management was cited by many participants. On the one hand, participants (more than 45) pointed out that there was not enough time to cover all the modules in depth, and that more time should be given to perform all activities efficiently and spend enough time in discussions. On average, 2 weeks instead of 5 days was recommended for the workshop duration. On the other hand, 23 participants agreed that time scheduling should be better organised, including a better respect of the agenda, so that one does not accelerate during some activities, as well a reduction of the number of hours per day, so that participants do not get tired. The second important remark (16 participants from 7 countries) was that one should organise similar workshops in other area of physics, such as mechanics, electricity, magnetism, electronics, solid state physics, and quantum mechanics. In Colombia, where the workshop was held in English and Spanish, problems in translation were reported (by 9 participants) and it was suggested that either the translation English-Spanish should be improved or the workshop should be given completely in Spanish. In India, where the number of participants was the highest, it was recommended that the number of participants (mentioned by 5 participants) be reduced, or divide participants into smaller groups (suggested by 2 participants). Other suggestions included: giving more materials to 
the participants during the workshop ( 8 participants), giving to participants the opportunity to design and prepare the materials by themselves ( 6 participants), giving a presentation on what is active leaning ( 5 participants), especially how to do it in class, what to expect and how to handle questions from the learners, having more practical work (4 participants), and having more daily life applications (3 participants).

\section{4) ADAPTING THE ALOP WORKSHOP TO VARIED EDUCATIONAL CONDITIONS}

A very important feature of the ALOP workshop is its well thought-out, sequential, participant-centered, inquirybased activities that use low-cost, locally-available materials/equipment. The basic principle followed is that the hands-on activities should be performed with locally sourced low-cost materials and with locally fabricated or homemade equipment. At every workshop preparation stage and for each and every module, this principle of local availability of materials is challenged and tested. It is not unusual for an ALOP facilitator to arrive at the workshop venue and then visit the local market and bargain for 20 plastic rulers, pencils, erasers, wax, torches, plastic containers etc.

Some materials and equipment for the training modules can be difficult to find locally in countries where ALOP workshops are held. For example, for module 1, geometrical optics, a semi-cylindrical transparent chamber is extensively used to demonstrate qualitatively the interaction of light rays with a transparent surface and arrive at the laws of reflection and refraction. As described in the training manual, this chamber "is a common item available in most physics departments. Such chambers are available from Sargent-Welch....." However, this is not so in many of the countries where the ALOP workshops are held and purchasing materials from Sargent-Welch in the USA will be too expensive. Preparing for a workshop in Algeria, one of the French-speaking facilitators from Tunisia took a transparent cylindrical container for cotton buds, cut it vertically in the middle and closed it with a rectangular piece of plexiglass. For prisms, those inexpensive ones available in Tunisia and made out of plexiglass, though not of very good quality, can work well. Another facilitator from Tunisia took note that white light torches using Tungsten lamps are becoming less and less available. Only those with LEDs are available. There is generally a lot of blur in those torches. The same facilitator travelled to a workshop venue, took white light sources using 4.5 -v flat batteries and planned to buy the batteries in the local shops. To her great surprise, the batteries were not available there.

For module 2, lenses and optics of the eye, the positive and negative lenses can be bought inexpensively from many optical shops and the optical benches can be made out of wood locally. For module 3, interference and diffraction, the experiments can be done using inexpensive laser pointers. For module 4, atmospheric optics, to demonstrate polarization, no alternative has been found for the linear polarizing filter that can only be bought from companies in the developed world. However, for the aquarium that is extensively used to simulate atmospheric phenomena, any transparent box or container (usually of chocolate candies) works very well. In one workshop venue, when the overhead projector became unavailable, torches and transparent glasses were used to demonstrate absorption, transmission and dispersion of white light. Modules 5 and 6, optical data transmission and wavelength division multiplexing, remain very special because many of the electronic components cannot be found in local shops in countries where ALOP workshops are held. Moreover, mounting these components require skill in soldering and care in handling of circuit boards. In many countries, importation of special components even for educational use is not easy to do.

Participants in ALOP workshops have also reported successfully adopting and demonstrating some of the ALOP experiments using locally sourced simple materials in classes in electromagnetism and introduction to quantum physics.

Facilitating in ALOP workshops and following the ALOP principle of local availability of materials require certain characteristics and attitudes. The ALOP program ensures that ALOP facilitators are sensitive to, and mindful of, the cultural, social and economic diversity of the workshop participants. Workshops have a mix of facilitators including some "local" or "regional" experts as well as international experts in physics education and optics. The program emphasizes the need to train additional local or regional resource persons so they can become facilitators for future ALOP workshops. After participating in an ALOP workshop, would-be facilitators commit themselves to master one or two modules, preparing materials, making the apparatus, redoing the activities and practicing presentation of the 
module with colleagues. The sustainability of the ALOP program depends on identifying and encouraging new facilitators who can organize second generation workshops in their respective countries or regions. The ALOP program has been particularly successful in reaching out to physics teachers in regions where English is not commonly used and being able to run workshops in the local language. As mentioned earlier, the ALOP Training Manual is now available in official English and French versions, and in draft forms in Spanish and Arabic.

In preparing for a workshop, an ALOP facilitator should be able to effectively communicate with the local organizers, especially if materials and apparatus are to be locally sourced and fabricated. This is a multicultural exercise which requires clearly explaining to the organizers by exchange of e-mails and photos how to fabricate the aquariums and optical benches, for example, to enable the local organizers to succeed in producing useful aquariums and optical benches.

As ALOP workshop facilitators arrive at the ALOP workshop site they come as well prepared as possible. Often problems arise in the venue (for example inability to darken the room) so that facilitators have to be very resourceful. This may mean several facilitators going off into town to find enough rolls of aluminum foil to black out windows while the rest of the team starts to set up for the first activity.

Sometimes things don't go as planned, for instance, when power was lost for a couple of days to the campus at Cape Coast, Ghana, where the temperature and humidity were both high. Adjustments were made to use battery-operated lighting and the workshop did not miss a beat, even without the benefit of cooling fan.

A few times some facilitators arrived at the workshop venue without their luggage which included the workshop materials. With the help of the organizers, the materials and apparatus were fabricated again and used in the workshop.

An ALOP workshop is held in a selected venue at the request of local organizers who are usually associated with a university, a physics department, or a research institute. Local organizers are encouraged to expose government and ministry officials, university administrators and local curriculum development experts to the goals of the ALOP workshop and involve them in organizing the training activity since any follow-up actions will depend on their support.

Even with an abundance of good will, local support-financial and in-kind-- is required for sustainability of any type of activity. As in developed countries, this kind of support requires lobbying and for this, local organizers of an ALOP workshop must be self-motivated and persuasive. For their serious and dedicated work, local organizers get the continual backup support of the ALOP team, and this contributes to the long-term success of the program.

What is striking to most people observing an ALOP activity for the first time is how hard the participants work, sometimes even under very difficult conditions. They become engaged in the activity-by its nature the active learning process engages the students who participate in it (in this case, the teachers) - and this alone stands out as a huge difference between the active learning environment and a typical classroom lecture session. The aspect of discovery, of not merely doing a laboratory exercise to demonstrate something "learned" in lecture, but to discover something new, to go through the process of prediction and observation, this is what an observer sees and takes away. It would be difficult to observe a student with glazed-over eyes, or struggling to stay awake. They may have come thinking that they would be taught everything they need to know - and thought that all they needed was a large pad of paper and a good pen--but they quickly get caught up with the process of discovering "concepts" for themselves with the guidance of the facilitators. This positive experience is what can motivate them to want to give the same experience to their own students.

It is rewarding to observe how the views of some of the participants change over the course of the five-day workshop. A significant number of academics who often have been teaching optics for many years find it hard to believe that their students can still harbor significant optics misconceptions even after instruction. But with the physics education research results presented, the active learning pedagogy explained, and their own experience of the PODS learning cycle, many of these academics end up becoming the strongest advocates for ALOP and the active learning philosophy it uses. 


\section{5) CONTINUING THE GOOD WORK}

One of the most important factors for the success of the project ALOP is that it continues to receive technical and financial support from the main project stakeholders, namely UNESCO, SPIE and the Abdus Salam International Centre for Theoretical Physics (ICTP). Moreover, the assistance provided by institutions in the host country, financial and in-kind, is invaluable.

With the ALOP Training Manual now available in English and French, and being developed in Spanish and Arabic, the present trend of training new facilitators who speak these languages and holding workshops in one of any of these languages shall continue. Training trainers in their native tongues is expected to enhance conceptual understanding and learning. The test results using the Light and Optics Conceptual Evaluation (LOCE) are also expected to improve accordingly.

The ALOP program shall continue to emphasize the need for participants who have attended ALOP workshops to work together to coordinate follow-up or second generation ALOP-style local and regional workshops. These followup workshops can start small, with one or two modules, with local facilitators who form a core group and commit themselves to master a module or two, preparing materials and sourcing them locally, making the apparatus, redoing the activities and practicing among themselves. These local groups are advised to keep in contact with the ALOP team and/or any of the project stakeholders. The important achievements of the Moroccan follow-up activities show that the contagious enthusiasm of a local core group who has won the support of the local education officials and institutions and has maintained interaction with the ALOP team, UNESCO, SPIE and ICTP, are key components of success.

Optics and photonics are ideal topics for teaching and learning materials, as the field becomes more interesting with miniaturized components that are becoming less expensive and more available, such as light-emitting diodes, laser diodes and photodetectors. Light is everywhere and its effects can be observed in the environment around us and can be used in many ways. Therefore, this topic is interesting not only to physics teachers, but also to science teachers and practitioners in other fields of scientific studies (engineering, metrology, optometry, meteorology, etc.).

\section{REFERENCES}

1. Laws, P., “A Lens into the World," AAPT Interactions, 38(1), 20-23 (2008).

2. http://www.uis.unesco.org, "New UIS projections on teacher shortages"

3. Alarcon, M., Arthurs, E., Ben Lakhdar, Z., Culaba, I., Lakshminarayanan, V., Maquiling, J., Mazzolini, A., Niemela, J., Sokoloff, D., "Active Learning in Optics and Photonics: Achievements and Outcomes to Date," Presented at the 2007 ETOP Conference, Ottawa, Canada.

4. Alarcon, M., Arthurs, E., Ben Lakhdar, Z., Culaba, I., Lakshminarayanan, V., Maquiling, J., Mazzolini, A., Niemela, J., Sokoloff, D., "Active Learning in Optics and Photonics: Experiences in Africa," ETOP040, Proceedings of the 2005 ETOP Conference, 161/416 - 163/416 (2005).

5. Alarcon, M., "Capacity building in Optics and Photonics by international collaboration," EWB1, Proceedings of the 2003 ETOP Conference. 